\title{
Addressing Racism in Hospital Pharmacy Practice Research
}

\author{
Lauren Bresee
}

DOI: https://doi.org/10.4212/cjhp.v74i4.3184

It is clear that racism has long existed in the Canadian health care system and that racism is a public health crisis, particularly for Indigenous and Black people in Canada. ${ }^{1-6}$ In addition to the known harms to patients that are due to racism in clinical practice, clinical research is also directly affected by racism.

When we conduct patient-based research, we want to ensure that the results of the study will be applicable to the broader patient population. We accomplish this aim by recruiting a representative study sample. However, important sociodemographic variables, including race and ethnicity, are often not reported in studies. ${ }^{7,8}$ In addition, participants in randomized controlled trials are more likely to be white, wealthy, and male. ${ }^{7}$ These factors limit both the ability to assess the relevance of the study results and the applicability of those results to nonwhite, non-male patients who are not wealthy.

To my knowledge, there is a paucity of research available that evaluates the impact of racism on patients in Canadian hospital pharmacy practice. As a result, it is unclear whether racism exists in hospital pharmacy practice, and if it does exist, how it affects patient outcomes. However, we do know that structural racism and health inequalities exist in other aspects of health care in Canada. ${ }^{3,4}$ Given the lack of currently available evidence, important research questions include whether structural racism exists in hospital pharmacy practice, how it affects patients, and how it can be addressed to ensure that all patients receive equitable care.

How can we start to address the barriers of racism in hospital pharmacy practice research? Decisions about health research funding, including funding for hospital pharmacy research, need to include the principles of equity, diversity, and inclusion. ${ }^{9}$ In addition, conducting and disseminating research about racism in Canadian hospital pharmacy is vital to addressing racism in our own individual practices. Also, information related to race and ethnicity should be reported in all research articles, both to identify whether there are barriers to participation in research for patients of certain races or ethnicities, and to determine the generalizability of the results beyond the study population. ${ }^{4}$ This is certainly not an exhaustive list of ways to address barriers due to racism in hospital pharmacy research; rather, it only serves to emphasize the need to continue this discussion with our colleagues in the weeks and months to come.

Racism has no place in society, and it certainly has no place in hospital pharmacy research. As stated in the National Association of Pharmacy Regulatory Authorities' white paper on the culture of professionalism in pharmacy: "Pharmacy as a profession, as well as all individuals who contribute to the profession, are starting important conversations about these issues and are recognizing the responsibility we have, as individuals and as a profession, to acknowledge that racism and discrimination exist within our society, our workplaces, and our profession and the importance of working towards a profession that embraces inclusion, diversity, and equity." ${ }^{10}$ We each need to take personal responsibility for preventing racism in hospital pharmacy practice and to continue those conversations to ensure that hospital pharmacy research also embraces inclusion, diversity, and equity.

\section{References}

1. Dryden O, Nnorom O. Time to dismantle systemic anti-Black racism in medicine in Canada. CMAJ. 2021;193(2):E55-7.

2. Mahabir DF, O’Campo P, Lofters A, Shankardass K, Salmon C, Muntaner C. Experiences of racism in Toronto's health care system: a concept mapping study. Int J Equity Health. 2021;20(1):Article 74.

3. Pan-Canadian Health Inequalities Reporting Initiative. Key health inequalities in Canada: a national portrait. Cat no. HP35-109/2018E1-PDF. Minister of Health, Public Health Agency of Canada; 2018 Aug [cited 2021 Jun 11]. Available from: https://www.canada.ca/content/ $\mathrm{dam} / \mathrm{phac}$-aspc/documents/services/publications/science-research/ key-health-inequalities-canada-national-portrait-executive-summary/ hir-full-report-eng.pdf

4. Racism and public health [position statement]. Canadian Public Health Association; 2018 Dec 17 [cited 2021 Jun 16]. Available from: https://www.cpha.ca/racism-and-public-health

5. McNally M, Martin D. First Nations, Inuit and Métis health: considerations for Canadian health leaders in the wake of the Truth and Reconciliation Commission of Canada report. Healthc Manage Forum. 2017;30(2):117-22.

6. Siddiqi AA, Wang S, Quinn K, Nguyen QC, Christy AD. Racial disparities in access to care under conditions of universal coverage. Am J Prev Med. 2016;50(2):220-5. 
7. Orkin AM, Nicoll G, Persaud N, Pinto AD. Reporting of sociodemographic variables in randomized clinical trials, 2014-2020. JAMA Netw Open. 2021;4(6):e2110700.

8. Khan M, Kobayashi K, Lee SM, Vang Z. (In)Visible minorities in Canadian health data and research. Population Change and Lifecourse Strategic Knowledge Cluster Discussion Paper Series. 2015 [cited 2021 Jun 16];3(1):Article 5. Available from: https://ir.lib.uwo.ca/cgi/ viewcontent.cgi?article $=1013 \&$ context $=$ pclc

9. Clifford T. CIHR's commitment to enhancing equity, diversity, and inclusion in the research funding system: a message from the Vice-President, Research Programs. Canadian Institutes of Health Research; 2020 Oct 14 [cited 2021 Jun 16]. Available from: https://cihr-irsc.gc.ca/e/52174.html

10. NAPRA Working Group. The culture of professionalism in pharmacy [white paper]. National Association of Pharmacy Regulatory Authorities; 2021 May [cited 2021 Jun 16]. Available from: https://napra.ca/ sites/default/files/2021-05/The\%20Culture\%20of\%20Professionalism \%20in\%20Pharmacy_May\%202021.pdf
Lauren Bresee, BScPharm, ACPR, MSc, PhD, is a Special Projects Advisor with the Canadian Agency for Drugs and Technologies in Health (CADTH), Ottawa, Ontario; an Adjunct Assistant Professor with the Department of Community Health Sciences, Cumming School of Medicine, University of Calgary, Calgary, Alberta; and a member of the O'Brien Institute for Public Health, University of Calgary. She is also an Associate Editor with the Canadian Journal of Hospital Pharmacy.

Competing interests: None declared.

Address correspondence to:

Dr Lauren Bresee

Canadian Agency for Drugs and Technologies in Health

865 Carling Avenue, Suite 600

Ottawa ON K1S 5 S8

email: LaurenB@cadth.ca

\section{ON THE FRONT COVER}

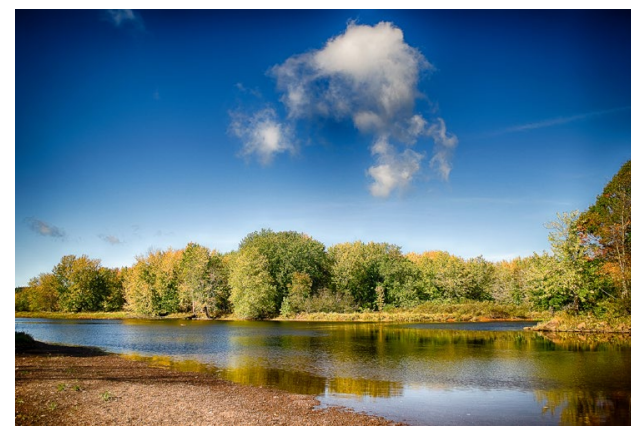

\section{Darlings Island, New Brunswick}

This photograph of Darlings Island, located northeast of Saint John, New Brunswick, was taken with a Nikon D5100 in the fall of 2012 by Joshua Bryant. Darlings Island is surrounded by several rivers, including Kennebecasis River and Hammond River. Many people enjoy kayaking and canoeing the rivers surrounding Darlings Island, and Hammond River is one of southern New Brunswick's best spots for Atlantic salmon. Josh works as a hospital telepharmacist for Northwest Telepharmacy Solutions. He enjoys hiking with his dog Hendrix, photography, playing guitar, and working out at the gym so that he can enjoy the occasional sweet.

The CJHP would be pleased to consider photographs featuring Canadian scenery taken by CSHP members for use on the front cover of the Journal. If you would like to submit a photograph, please send an electronic copy (minimum resolution $300 \mathrm{dpi}$ ) to publications@cshp.ca. 